\title{
New strategies for treatment of inflammatory bowel
}

\section{disease}

\section{Ole Haagen Nielsen*}

Department of Gastroenterology, Medical Section, Herlev Hospital, University of Copenhagen, Copenhagen, Denmark

\section{Edited by:}

Giovanni Cammarota, School of Medicine and Surgery, Catholic University, Italy

Reviewed by:

Ludovico Abenavoli, University Magna Graecia, Italy

Alejandro Piscoya, Universidad Peruana de Ciencias Aplicadas, Peru

\section{*Correspondence:}

Ole Haagen Nielsen, Department of Gastroenterology D112M, Herlev Hospital, University of Copenhagen, 75 Herlev Ringvej, Herlev, Copenhagen DK-2730, Denmark e-mail:ohn@dadlnet.dk
The etiology of inflammatory bowel disease (IBD), of which ulcerative colitis (UC) and Crohn's disease (CD) are the two most prevailing entities, is unknown. However, IBD is characterized by an imbalanced synthesis of pro-inflammatory mediators of the inflamed intestine, and for more than a decade tumor necrosis factor-(TNF) $\alpha$ has been a major target for monoclonal antibody therapy. However, TNF inhibitors are not useful for one third of all patients (i.e. "primary failures"), and further one third lose effect over time ("secondary failures"). Therefore, other strategies have in later years been developed including monoclonal antibodies targeting the interleukin (IL)-6 family of receptors (the p40 subunit of IL-12/IL-23) as well as monoclonal antibodies inhibiting adhesion molecules (the $\alpha_{4} \beta_{7}$ heterodimers), which direct leukocytes to the intestinal mucosa. Recently, small molecules, which are inhibitors of Janus kinases (JAKs), hold promise with a tolerable safety profile and efficacy in UC, and the field of nanomedicine is emerging with siRNAs loaded into polyactide nanoparticles that may silence gene transcripts at sites of intestinal inflammation. Thus, drug development for IBD holds great promise, and patients as well as their treating physicians can be hopeful for the future.
Inflammatory bowel disease (IBD), of which ulcerative colitis (UC) and Crohn's disease (CD) are the two prevailing entities, constitutes an important global public health problem with increasing incidence (1). The disease is multifactorial driven mainly by an inappropriate immune response to gut microbes in a genetically predisposed host (2). IBD occurs worldwide but its incidence and prevalence vary widely among geographic regions (1). The increased prevalence will as a consequence translate into higher health care expenditures, and patient costs for IBD, which are higher than for asthma, hypertension, and chronic obstructive pulmonary disease (3), will become increasingly relevant to the economy as a whole (4). Additionally, recent mortality data have revealed an increase in intermediate and long-term mortality among patients with IBD with even higher percentages for patients diagnosed as children or adolescents (5).

Conventional management of IBD follow a step-up strategy $(6,7)$, and for several years the treatment options were glucocorticoids, immunomodulators [i.e. thiopurines and methotrexate (the latter for CD only)], cyclosporine, 5-aminosalicylic acid (for UC only), and antibiotics $(8,9)$, but in later years there has been a landmark of discoveries and advancements in our understanding of the innate and adaptive immune responses. These discoveries have been paralleled by an exponential increase in the number of new and investigational therapeutic targets briefly mentioned in the following (10).

\section{TNF INHIBITORS}

For one and a half decade, the treatment of more than 1.3 million patients with tumor necrosis factor (TNF- $\alpha$ ) inhibitors have generated huge amounts of safety and long-term efficacy data.
This class include monoclonal antibodies of which infliximab was first on the market, followed by adalimumab, certolizumab pegol (a Fab' fragment), and recently golimumab (Table 1) (11). One of the drawbacks attributed to biologics is, however, the loss of response caused by antibody formation and the costs associated with long-term therapy (12). Notably, around 33\% fail to respond to TNF inhibitors and another third of all patients lose response over time and need to be switched to another TNF inhibitor (11). Nevertheless, prospective randomized controlled trials have demonstrated that combination therapy with thiopurines and infliximab is superior to either agent alone in both $\mathrm{UC}$ and $\mathrm{CD}(13$, 14). Thus, combination therapy reduces anti-infliximab antibodies and approximately doubles the level of infliximab in circulation $(13,15)$. Altogether, these data suggest that concomitant therapy leads to optimized clinical outcomes and that the use of combination therapy in IBD is likely to increase (16). Nevertheless, it should be noticed that the underlying modes of action of the available TNF inhibitors are rather complex (17).

There is an apparent shift in cost profile from surgery and hospitalization toward TNF inhibitor treatment, but the relatively consistent overall total costs suggest that the high cost of these biologics are partly compensated for by the reduction in surgery and hospitalization rates (18-20). Whether long-term TNF inhibitor therapy is cost effective in IBD has yet to be determined, at least from the society's perspective. Even with early introduction to a TNF inhibitor, one in five patients with UC (21) and seven of 10 patients with CD (22) will eventually require colectomy or small bowel resections. However, careful monitoring of changes in the cost of care in IBD will ensure that timely economic decisions can be made. 
Table 1 | Novel drugs for treatment of inflammatory bowel disease.

\begin{tabular}{|c|c|c|c|c|}
\hline Structure & Drug & Route of administration & Indications & Target(s \\
\hline & Infliximab (75\% human, 25\% mouse) & Intravenous & $C D$ and $U C$ & TNF- $\alpha$ \\
\hline & Adalimumab (100\% human) & Subcutaneous injection & $C D$ and $U C$ & TNF- $\alpha$ \\
\hline & Golimumab (100\% human) & Subcutaneous injection & UC & TNF- $\alpha$ \\
\hline & Certolizumab pegol (humanized Fab fragment) & Subcutaneous injection & $C D$ & TNF- $\alpha$ \\
\hline
\end{tabular}

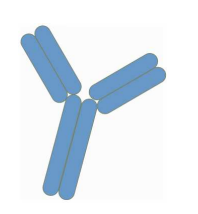

Ustekinumab (100\% human)

Natalizumab (humanized)

Vedolizumab (humanized)

Tofacitinib (small molecule)

siRNA (nanomolecule)
Intravenous

Intravenous

Oral

Oral
$C D$

$\mathrm{CD}$ and $\mathrm{UC}$

UC

$C D$ and $U C$

$\alpha 4 \beta 1$ and $\alpha 4 \beta 7$

IL-12 and IL-23

JAK1 and JAK3

siRNA targeting

TNF- $\alpha$ transcripts

CD, Crohn's disease; UC, ulcerative colitis; TNF, tumor necrosis factor; IL, interleukin; JAK, Janus kinase; siRNA, small interfering RNA. The double-stranded structure is degraded to single strands, and the red part is bound to target mRNA and directs it for cleavage). The structure of antibodies, small molecule or siRNA is shown (the human antibody part of TNF inhibitors is in green color). 
Regarding the combination therapy with thiopurines and TNF inhibitors, some but not all studies show an association between this combination and adverse events, particularly non-Hodgkin lymphoma, other cancers, and opportunistic infections $(23,24)$. More information is needed to conclude which patients benefit from combination therapy and what is the optimal duration of treatment (11). Further, controversy exists regarding which patients with IBD require early aggressive treatment versus those who can be treated with the more conventional step-up strategy. Preliminary data for top-down therapy in CD suggest an improvement in the natural history (25). Thus, predictors of aggressive IBD may be helpful in risk stratification and to decide who will benefit from early aggressive therapy. Improved understanding of the pathogenesis of IBD as well as biomarker identification will hopefully facilitate risk stratification and identification of patients who will benefit from early top-down treatment $(26,27)$.

\section{THERAPEUTICS OTHER THAN TNF INHIBITORS}

As there is a large unmet need in the therapeutic options for patients with IBD, targeting molecular pathways other than TNF- $\alpha$ is a recent approach in the management of IBD (Table 1) (28).

The efficacy of ustekinumab, a monoclonal antibody targeting the interleukin (IL)-6 family of receptors, namely the p40 subunit of IL-12/IL-23 (29), has been investigated in CD. While the clinical remission rates in the induction therapy did not differ significantly from placebo at week 6 , the maintenance therapy with ustekinumab every 8 weeks resulted in a significantly higher clinical remission at week $22(42 \%)$ as compared with placebo $(27 \%$, $p=0.03$ ) among patients with anti-TNF resistance (30).

Adhesion molecules are also considered important targets for therapeutic intervention in IBD, and antibodies directed against cell-adhesion molecules have been developed. They suppress inflammation through inhibition of leukocyte adhesion and transmigration into inflamed tissues. The first approved adhesion inhibitor targeting the $\alpha_{4}$ integrin (natalizumab) was found to be effective for both induction and maintenance of CD (31, 32). However, its clinical use was hampered as cases of the fatal progressive multifocal leukoencephalopathy (PML) caused by reactivation of JC virus have been reported (33). Nonetheless, natalizumab has been approved by the FDA for CD with a "black box warning" for patients who are refractory to conventional therapy, including TNF inhibitors. However, patients must be free from concomitant immunosuppressants and screened for JC virus antibodies before this drug is administered, although the predictive value of this test for PML has been a matter of debate (33). Natalizumab-associated PML is caused by nonselective inhibition of the $\alpha_{4} \beta_{1}$ heterodimers, which directs leukocytes not only to intestinal mucosa but also to the central nervous system. Therefore, a "second generation" drug class, which specifically inhibit intestinal $\beta_{7}$ integrins have been developed (vedolizumab). Although no patients treated with vedolizumab so far acquired the infection, future occurrences should not be excluded, especially as few patients developed transient JCV viremia albeit without clinical or MRI findings (34). Hence, a FDA advisory panel concluded in December 2013 that the benefits of these new drugs may outweigh the potential risk of the drug causing PML.
Vedolizumab has been studied in UC and $\operatorname{CD}(35,36)$ and after 52 weeks of treatment, $45 \%$ of patients with UC treated with vedolizumab were corticosteroid-free compared to $16 \%$ in the placebo arm, and $56 \%$ had mucosal healing (20\% in the placebo arm) (35). In CD the effect was somewhat weaker (37 versus $22 \%$ in the placebo arm) (36). The favorable safety profile of vedolizumab and the stable response and remission rates over 1 year are true assets for this compound.

Apart from vedolizumab, other anti- $\beta_{7}$ antibodies are in the pipeline including etrolizumab (specific for leukocyte $\beta_{7}$ integrin and E-cadherin) (37) and PF-00547,659 specific for endothelial MAdCAM-1 (38). The latter mentioned drug has, however, not been associated with activation of JCV viremia (39).

Small molecules such as tofacitinib, a non-biologic oral inhibitor of Janus kinases (JAKs) selective for JAK1 and JAK3 (40, 41 ), hold promise with a tolerable safety profile and in contrast to the drugs already mentioned it can be taken orally (42). Additionally, small molecules are less expensive than antibodies. The JAK signaling pathways are responsible for signal transduction of various cytokine receptors involved in both the innate and adaptive immune compartments of IBD $(43,44)$. In UC tofacitinib has been very successful with a clinical response at week 8 of up to $78 \%$ compared with $42 \%$ in the placebo arm (41). However, this drug has no efficacy in CD (45).

Nanomedicine is an emerging area using nanotechnology for medical purposes. It refers to the utilization of molecules at the nanometer scale, and its potential is to turn molecular discoveries arising from systems biology into benefit for patients $(46,47)$. Nanomedicine allows targeted delivery of drugs to sites of interest (e.g., inflamed intestine) (48), and may in this way minimize the required dosing and side-effects (49). Thus, preclinical investigations with oral TNF- $\alpha$-targeting siRNAs loaded into polyactide nanoparticles capable of localizing and silencing gene transcripts at sites of intestinal inflammation are promising $(50,51)$. Although nanomedicine is still in the making, the size-dependent accumulation of nanocarriers at sites of inflamed intestine can be utilized to increase clinical efficacy, diminish side-effects and open for new delivery routes for fragile (bio)molecules. Taken together, this novel principle of therapy has a huge potential for management of IBD in the future (52).

Head-to-head comparisons of the new agents mentioned with existing therapies would advance the care of our patients and enable the best strategy for the individuals to be selected.

\section{CONCLUSION}

A number of important discoveries will impact the future of IBD therapy, and the use of biomarkers and imaging will increase in the years to come. Pharmacokinetics and therapeutic monitoring will be used to customize drug dosing for individual patients. Treatment end-points will evolve from symptoms to mucosal healing; the prevention of structural damage and the prevention of disability. Concomitant therapy with thiopurines and TNF inhibitors will be used more frequently. The continued discovery of novel therapeutic targets will provide rationale for a rich pipeline of future therapeutics, which will change clinical practice at centers treating IBD. 
Due to the discovery of susceptibility genes, novel cell-subsets, and insights into antigen-processing and cell-signaling, we have nowadays acquired a much better understanding of the basis of IBD $(10,17)$. With the arrival of targeted therapy in the form of monoclonal antibodies, small molecule inhibitors, and RNAinterference-based therapy, we will be given the tools to manipulate specific inflammatory processes. By integrating these technologies and the expanding number of candidate pathways, several new medications can be expected to reach clinical trials in the coming years. This requires a continuous revealing of biological mechanisms, drug kinetics, and potential side-effects. Thus, a close collaboration between clinicians and research laboratories, other specialties as well as the pharmaceutical industry seems to be of paramount importance in creating progress in this expanding field.

Drug development for IBD holds great promise and patients as well as gastroenterologists can be hopeful for the future.

\section{REFERENCES}

1. Molodecky NA, Soon IS, Rabi DM, Ghali WA, Ferris M, Chernoff G, et al. Increasing incidence and prevalence of the inflammatory bowel diseases with time, based on systematic review. Gastroenterology (2012) 142:46-54. doi:10. 1053/j.gastro.2011.10.001

2. Abraham C, Cho JH. Inflammatory bowel disease. N Engl J Med (2009) 361:2066-78. doi:10.1056/NEJMra0804647

3. Gunnarsson C, Chen J, Rizzo JA, Ladapo JA, Lofland JH. Direct health care insurer and out-of-pocket expenditures of inflammatory bowel disease: evidence from a US national survey. Dig Dis Sci (2012) 57:3080-91. doi:10.1007/ s10620-012-2289-y

4. Odes S. How expensive is inflammatory bowel disease? A critical analysis. World J Gastroenterol (2008) 14:6641-7. doi:10.3748/wjg.14.6641

5. Jess T, Frisch M, Simonsen J. Trends in overall and cause-specific mortality among patients with inflammatory bowel disease from 1982 to 2010. Clin Gastroenterol Hepatol (2013) 11:43-8. doi:10.1016/j.cgh.2012.09.026

6. Dignass A, Van Assche G, Lindsay JO, Lémann M, Söderholm J, Colombel JF, et al. The second European evidence-based consensus on the diagnosis and management of Crohn's disease: current management. J Crohns Colitis (2010) 4:28-62. doi:10.1016/j.crohns.2009.12.002

7. Kornbluth A, Sachar DB. Ulcerative colitis practice guidelines in adults: American college of gastroenterology, practice parameters committee. Am J Gastroenterol (2010) 105:501-23. doi:10.1038/ajg.2009.727

8. Baumgart DC, Sandborn WJ. Crohn's disease. Lancet (2012) 380:1590-605. doi:10.1016/S0140-6736(12)60026-9

9. Danese S, Fiocchi C. Ulcerative colitis. N Engl J Med (2011) 365:1713-25. doi:10.1056/NEJMra1102942

10. Danese S. New therapies for inflammatory bowel disease: from the bench to the bedside. Gut (2012) 61:918-32. doi:10.1136/gutjnl-2011-300904

11. Nielsen $\mathrm{OH}$, Ainsworth MA. Tumor necrosis factor inhibitors for inflammatory bowel disease. N Engl J Med (2013) 369:754-62. doi:10.1056/NEJMct1209614

12. Steenholdt C, Brynskov J, Thomsen OO, Munck LK, Fallingborg J, Christensen LA, et al. Individualised therapy is more cost-effective than dose intensification in patients with Crohn's disease who lose response to anti-TNF treatment: a randomised, controlled trial. Gut (2013). doi:10.1136/gutjnl-2013-305279

13. Colombel JF, Sandborn WJ, Reinisch W, Mantzaris GJ, Kornbluth A, Rachmilewitz D, et al. Infliximab, azathioprine, or combination therapy for Crohn's disease. N Engl J Med (2010) 362:1383-95. doi:10.1056/NEJMoa0904492

14. Panccione R, Ghosh S, Middleton S, Marquez JR, Scott BB, Flint L, et al. Combination therapy with infliximab and azathioprine is superior to monotherapy with either agent in ulcerative colitis. Gastroenterology (2014) 146(2):392-400.e3. doi:10.1053/j.gastro.2013.10.052

15. Lichtenstein GR, Diamond RH, Wagner CL, Fasanmade AA, Olson AD, Marano $\mathrm{CW}$, et al. Clinical trial: benefits and risks of immunomodulators and maintenance infliximab for IBD-subgroup analyses across four randomized trials. Aliment Pharmacol Ther (2009) 30:210-26. doi:10.1111/j.1365-2036.2009.04027.x
16. Sandborn WJ. The future of inflammatory bowel disease therapy: where do we go from here? Dig Dis (2012) 30(Suppl 3):140-4. doi:10.1159/000342742

17. Coskun $\mathrm{M}$, Nielsen $\mathrm{OH}$. Tumor necrosis factor inhibitors for inflammatory bowel disease. N Engl J Med (2013) 369:2561-2. doi:10.1056/NEJMc1312800

18. Rungoe C, Langholz E, Andersson M, Basit S, Nielsen NM, Wohlfahrt J, et al. Changes in medical treatment and surgery rates in inflammatory bowel disease: a nationwide cohort study 1979-2011. Gut (2013). doi:10.1136/gutjnl-2013305607

19. van der Valk ME, Mangen MJ, Leenders M, Dijkstra G, van Bodegraven AA, Fidder HH, et al. Healthcare costs of inflammatory bowel disease have shifted from hospitalisation and surgery towards anti-TNFalpha therapy: results from the COIN study. Gut (2014) 63:72-9. doi:10.1136/gutjnl-2012-303376

20. Louis E, Mary JY, Vernier-Massouille G, Grimaud JC, Bouhnik Y, Laharie D, et al. Maintenance of remission among patients with Crohn's disease on antimetabolite therapy after infliximab therapy is stopped. Gastroenterology (2012) 142:63-70. doi:10.1053/j.gastro.2011.09.034

21. Sandborn WJ, Rutgeerts P, Feagan BG, Reinisch W, Olson A, Johanns J, et al. Colectomy rate comparison after treatment of ulcerative colitis with placebo or infliximab. Gastroenterology (2009) 137:1250-60. doi:10.1053/j.gastro.2009. 06.061

22. Lazarev M, Ullman T, Schraut WH, Kip KE, Saul M, Regueiro M. Small bowel resection rates in Crohn's disease and the indication for surgery over time: experience from a large tertiary care center. Inflamm Bowel Dis (2010) 16:830-5. doi:10.1002/ibd.21118

23. Siegel CA, Marden SM, Persing SM, Larson RJ, Sands BE. Risk of lymphoma associated with combination anti-tumor necrosis factor and immunomodulator therapy for the treatment of Crohn's disease: a meta-analysis. Clin Gastroenterol Hepatol (2009) 7:874-81. doi:10.1016/j.cgh.2009.01.004

24. Toruner M, Loftus EVJr, Harmsen WS, Zinsmeister AR, Orenstein R, Sandborn WJ, et al. Risk factors for opportunistic infections in patients with inflammatory bowel disease. Gastroenterology (2008) 134:929-36. doi:10.1053/j.gastro. 2008.01.012

25. D'Haens G, Baert F, van Assche G, Caenepeel P, Vergauwe P, Tuynman H, et al. Early combined immunosuppression or conventional management in patients with newly diagnosed Crohn's disease: an open randomised trial. Lancet (2008) 371:660-7. doi:10.1016/S0140-6736(08)60863-6

26. Mow WS, Vasiliauskas EA, Lin YC, Fleshner PR, Papadakis KA, Taylor KD, et al. Association of antibody responses to microbial antigens and complications of small bowel Crohn's disease. Gastroenterology (2004) 126:414-24. doi:10.1053/j.gastro.2003.11.015

27. Vasiliauskas EA, Kam LY, Karp LC, Gaiennie J, Yang H, Targan SR. Marker antibody expression stratifies Crohn's disease into immunologically homogeneous subgroups with distinct clinical characteristics. Gut (2000) 47:487-96. doi:10.1136/gut.47.4.487

28. Pedersen J, Coskun M, Soendergaard C, Salem M, Nielsen OH. Inflammatory pathways of importance for management of inflammatory bowel disease. World J Gastroenterol (2014) 20:64-77. doi:10.3748/wjg.v20.i1.64

29. Kobayashi M, Fitz L, Ryan M, Hewick RM, Clark SC, Chan S, et al. Identification and purification of natural killer cell stimulatory factor (NKSF), a cytokine with multiple biologic effects on human lymphocytes. J Exp Med (1989) 170:827-45. doi:10.1084/jem.170.3.827

30. Sandborn WJ, Gasink C, Gao LL, Blank MA, Johanns J, Guzzo C, et al. Ustekinumab induction and maintenance therapy in refractory Crohn's disease. N Engl J Med (2012) 367:1519-28. doi:10.1056/NEJMoa1203572

31. Sandborn WJ, Colombel JF, Enns R, Feagan BG, Hanauer SB, Lawrance IC, et al. Natalizumab induction and maintenance therapy for Crohn's disease. $N$ Engl J Med (2005) 353:1912-25. doi:10.1056/NEJMoa043335

32. Targan SR, Feagan BG, Fedorak RN, Lashner BA, Panaccione R, Present DH, et al. Natalizumab for the treatment of active Crohn's disease: results of the ENCORE Trial. Gastroenterology (2007) 132:1672-83. doi:10.1053/j.gastro.2007.03.024

33. Bloomgren G, Richman S, Hotermans C, Subramanyam M, Goelz S, Natarajan A, et al. Risk of natalizumab-associated progressive multifocal leukoencephalopathy. N Engl J Med (2012) 366:1870-80. doi:10.1056/NEJMoa1107829

34. Govani SM, Waljee AK, Higgins PD. Anti-adhesion therapies and the rule of 3 for rare events. Am J Gastroenterol (2013) 108:1831-2. doi:10.1038/ajg.2013.141

35. Feagan BG, Rutgeerts P, Sands BE, Hanauer S, Colombel JF, Sandborn WJ, et al. Vedolizumab as induction and maintenance therapy for ulcerative colitis. NEngl J Med (2013) 369:699-710. doi:10.1056/NEJMoa1215734 
36. Sandborn WJ, Feagan BG, Rutgeerts P, Hanauer S, Colombel JF, Sands BE, et al. Vedolizumab as induction and maintenance therapy for Crohn's disease. N Engl J Med (2013) 369:711-21. doi:10.1056/NEJMoa1215739

37. Rutgeerts PJ, Fedorak RN, Hommes DW, Sturm A, Baumgart DC, Bressler B, et al. A randomised phase I study of etrolizumab (rhuMAb beta7) in moderate to severe ulcerative colitis. Gut (2013) 62:1122-30. doi:10.1136/gutjnl-2011301769

38. Vermeire S, Ghosh S, Panes J, Dahlerup JF, Luegering A, Sirotiakova J, et al. The mucosal addressin cell adhesion molecule antibody PF-00547,659 in ulcerative colitis: a randomised study. Gut (2011) 60:1068-75. doi:10.1136/gut.2010. 226548

39. D’Haens G, Vermeire S, Cataldi F, Vogelsang H, Allez M, Desreumaux P, et al. Anti-MAdCAM monoclonal antibody PF-005476659 does not affect immune surveillance in the central nervous system of anti-TNF and immunesuppressant experienced Crohn's disease patients who are anti-TNF inadequate responders: results from the TOSCA study. J Crohns Colitis (2014) 8(Suppl 1):S4-5. doi:10.1016/S1873-9946(14)60008-8

40. Müller M, Briscoe J, Laxton C, Guschin D, Ziemiecki A, Silvennoinen O, et al. The protein tyrosine kinase JAK1 complements defects in interferon-alpha/beta and -gamma signal transduction. Nature (1993) 366:129-35. doi:10.1038/366129a0

41. Sandborn WJ, Ghosh S, Panes J, Vranic I, Su C, Rousell S, et al. Tofacitinib, an oral Janus kinase inhibitor, in active ulcerative colitis. N Engl J Med (2012) 367:616-24. doi:10.1056/NEJMoa1112168

42. Vuitton L, Koch S, Peyrin-Biroulet L. Janus kinase inhibition with tofacitinib: changing the face of inflammatory bowel disease treatment. Curr Drug Targets (2013) 14:1385-91. doi:10.2174/13894501113149990160

43. Coskun M, Salem M, Pedersen J, Nielsen OH. Involvement of JAK/STAT signaling in the pathogenesis of inflammatory bowel disease. Pharmacol Res (2013) 76:1-8. doi:10.1016/j.phrs.2013.06.007

44. Ghoreschi K, Laurence A, O'Shea JJ. Janus kinases in immune cell signaling. Immunol Rev (2009) 228:273-87. doi:10.1111/j.1600-065X.2008.00754.X

45. Sandborn WJ, Ghosh S, Panes J, Vranic I, Wang W, Niezychowski W, et al. Randomized study of CP-690,550, an oral Janus kinase inhibitor, in active Crohn's disease. Gastroenterology (2011) 140:S-124. doi:10.1016/j.cgh.2014.01.029

46. Boulaiz H, Alvarez PJ, Ramirez A, Marchal JA, Prados J, Rodríguez-Serrano F, et al. Nanomedicine: application areas and development prospects. Int J Mol Sci (2011) 12:3303-21. doi:10.3390/ijms12053303
47. Moghimi SM, Hunter AC, Murray JC. Nanomedicine: current status and future prospects. FASEB J (2005) 19:311-30. doi:10.1096/fj.04-2747rev

48. Xiao B, Merlin D. Oral colon-specific therapeutic approaches toward treatment of inflammatory bowel disease. Expert Opin Drug Deliv (2012) 9:1393-407. doi:10.1517/17425247.2012.730517

49. Pichai MV, Ferguson LR. Potential prospects of nanomedicine for targeted therapeutics in inflammatory bowel diseases. World J Gastroenterol (2012) 18:2895-901. doi:10.3748/wjg.v18.i23.2895

50. Laroui H, Theiss AL, Yan Y, Dalmasso G, Nguyen HT, Sitaraman SV, et al. Functional TNFalpha gene silencing mediated by polyethyleneimine/TNFalpha siRNA nanocomplexes in inflamed colon. Biomaterials (2011) 32:1218-28. doi:10.1016/j.biomaterials.2010.09.062

51. Wilson DS, Dalmasso G, Wang L, Sitaraman SV, Merlin D, Murthy N. Orally delivered thioketal nanoparticles loaded with TNF-alpha-siRNA target inflammation and inhibit gene expression in the intestines. Nat Mater (2010) 9:923-8. doi: 10.1038/nmat2859

52. Ali H, Collnot E-M, Windberg M, Claus-Michael L. Nanomedicines for the treatment of inflammatory bowel diseases. Eur J Nanomed (2013) 5:23-38. doi:10.1515/ejnm-2013-0004

Conflict of Interest Statement: The author declares that the research was conducted in the absence of any commercial or financial relationships that could be construed as a potential conflict of interest.

Received: 10 January 2014; paper pending published: 11 February 2014; accepted: 08 March 2014; published online: 24 March 2014.

Citation: Nielsen $\mathrm{OH}$ (2014) New strategies for treatment of inflammatory bowel disease. Front. Med. 1:3. doi: 10.3389/fmed.2014.00003

This article was submitted to Gastroenterology, a section of the journal Frontiers in Medicine.

Copyright $(\odot) 2014$ Nielsen. This is an open-access article distributed under the terms of the Creative Commons Attribution License (CC BY). The use, distribution or reproduction in other forums is permitted, provided the original author(s) or licensor are credited and that the original publication in this journal is cited, in accordance with accepted academic practice. No use, distribution or reproduction is permitted which does not comply with these terms. 